\title{
Of what benefit and to whom? Linking Australian humanities research with its 'end users'
}

\section{Tim Pitman \& Judith E. Berman}

To cite this article: Tim Pitman \& Judith E. Berman (2009) Of what benefit and to whom? Linking Australian humanities research with its 'end users', Journal of Higher Education Policy and Management, 31:4, 315-326, DOI: 10.1080/13600800903191955

To link to this article: https://doi.org/10.1080/13600800903191955

$$
\text { 曲 Published online: } 02 \text { Oct } 2009 .
$$

Submit your article to this journal

山ll Article views: 137

Q View related articles $\asymp$

4 Citing articles: 7 View citing articles 


\title{
Of what benefit and to whom? Linking Australian humanities research with its 'end users'
}

Tim Pitman* and Judith E. Berman

\author{
University of Western Australia, Perth, Australia
}

\begin{abstract}
There is increasing pressure for university researchers to secure 'end-user' support for their research projects. Yet the ways in which this imperative affects humanities researchers, operating in a science-centric funding environment, have not yet been fully explored. This paper presents the findings of an empirical study into the experiences of humanities researchers in securing competitive national funding for research involving collaborations with the private and public sector. It also provides quantitative data as to the funding behaviour of one of Australia's peak research funding bodies, the Australian Research Council (ARC). The findings clearly show that humanities researchers struggle to secure support for their research. There is also evidence to suggest that, despite rhetorical support from the ARC that it values research which provides cultural benefit, it too particularly prioritises research that promises economic advantages for both the project's partners and wider community.
\end{abstract}

Keywords: higher education policy; humanities; research funding

\section{Introduction}

In recent times, much has been written about the mounting need for Australian universities to secure alternative (i.e. non-government) financial support for their research programmes (Kirkland, 2008; Lazarevski, Irvine \& Dolnicar, 2008). In particular, research funding that has been secured as part of a competitive, peer-reviewed process carries with it an elite status (Berman, 2008; Marinova \& Newman, 2008; Wood \& Meek, 2002). Various arguments have been promoted as to the benefits of creating a culture of entrepreneurship in universities. These arguments include: that it increases the global competitiveness of a nation's higher education sector (Marginson, 2006); that research perceived of being of value to end users will attract their support, thus increasing the capacity of the institution to do more and higher quality research in these areas (Shattock, 1999); that it enhances the relevance and application of the research (Buys \& Bursnall, 2007) and - perhaps overriding all other motivations - that encouraging the notion of an entrepreneurial university can reduce the funding responsibilities of government (Yokoyama, 2006).

The ways in which universities react to these external factors will, in turn, affect the behaviour of their research staff. Increasingly, universities are implementing funding formulas that create internal 'performance economies' (Marginson, 2000, p. 100). Individuals are assessed not only on outputs (e.g. publications, conference presentations etc.) but more

*Corresponding author. Email: tim.pitman@uwa.edu.au

ISSN 1360-080X print/ISSN 1469-9508 online (C) 2009 Association for Tertiary Education Management and the 
and more upon on their ability to attract research income. Indeed, some have argued that this ability is now being used as a proxy for research quality (Goldsworthy, 2008). There is, to date, no evidence that strategies to address the imperative to secure external research funding, at either the macro (i.e. government) or meso (i.e. university) level, differentiate between fields of research. In other words, humanities scholars are as equally expected to secure these funds as, say, social or natural scientists.

This provides a potential challenge for researchers in the humanities, as the ongoing cultural change in Australian universities is largely predicated on an assumption that what works for science researchers (and, to a slightly lesser extent, social science researchers) will apply equally to those in the humanities. Yet there is evidence that the academic department is a critical unit of analysis in higher education. A typical research university will allocate resources differently across disciplines and assess the quality of their research on very different criteria (Lee, 2007). Consequently, assessing what research is worthy of funding will vary across research disciplines. One commonality, however, is that success in research funding will enhance the standing of the institution. Research universities cannot evade the challenges posed by global rankings, most notably the Shanghai Jiao Tong University rankings, which favour universities that are very strong in the sciences (Marginson, 2007). The significant organisational changes that have occurred in research-intensive institutions and universities during the past two decades reveal, first, an expectation that research outcomes should have demonstrable economic or social (as opposed to cultural or esoteric) advantage to the nation; and, second, underlying business principles and practices to translate (scientific) research into commercial outcomes (Turpin \& Deville, 1995).

Yet, at the same time, both government and universities are eager to assure the humanities of the continued relevance and importance of their research. In September 2008, the Minister for Innovation, Industry, Science and Research, Kim Carr, made the following statement in an address to the National Press Club:

... [T]he humanities, arts and social sciences are critical. They will give us the ideas, the language and the self awareness we need to make change happen ... These disciplines have to be on the same footing as the physical and life sciences. This is more than a matter of courtesy. It is a matter of necessity . . . I believe the creative arts - and the humanities and the social sciences - make a terrible mistake when they claim support on the basis of their commercial value. Whatever they may be worth in the marketplace, it is their intrinsic value we should treasure them for. We should support these disciplines because they give us pleasure, knowledge, meaning and inspiration. No other pay-off is required. (Carr, 2008)

How humanities researchers secure project funding in a science-centric funding environment is of great importance to education policy actors in Australia. Furthermore, the experiences of the Australian higher education sector have relevance to other countries facing similar research funding and policy environments.

\section{The study}

To date, there have been few empirical studies into the experiences of researchers from the humanities in the environment described above. For the present study, the authors sought to understand how a universal imperative (i.e. the need to seek external funding) affected researchers from the humanities in comparison with those from other disciplines. To do this, a specific funding scheme was targeted; namely, the Linkage Funding Scheme (hereafter referred to as 'Linkage'), which is administered by the Australian Research Council (ARC). The ARC promotes the Linkage scheme as a mechanism to encourage and 
develop long-term strategic research alliances between higher education organisations and other organisations (ARC, 2008, p. 9). Projects from all fields of study are encouraged and are not required to have any direct commercial application. The ARC states that it will fund all types of research including 'pure basic research which is experimental and theoretical work undertaken to acquire new knowledge without looking for long-term benefits other than the advancement of knowledge' (ARC, 2008. p. 16). Universities can form alliances with not only commercial organisations but also federal, State and local government agencies, not-for-profit organisations (NFP), and national and international research facilities, including universities in other countries. Thus, the Linkage scheme provided an ideal focus for this study for the following reasons:

1. It requires researchers to attract end-user support for their projects, thus addressing the imperative to seek external funding.

2. It is open to researchers from all disciplines and promotes itself as having no bias for any particular research field.

3. It claims to support equally research with economic or social or cultural benefit. and

4. It does not encourage philanthropic support - researchers are required to demonstrate the relevance and value of their research to both end-users and the wider community.

The Linkage scheme is one of the two 'flagship' funding schemes of the ARC; the other being the Discovery scheme. However, unlike Linkage, the Discovery scheme does not require researchers to seek matching funding from a partner organisation, and therefore fell outside the scope of the present study. The authors adopted a discipline-specific approach to an analysis of Linkage scheme outcomes, to assess the experiences of researchers from the humanities compared with those of the social science, science and applied technologies researchers. It is acknowledged that these concepts ('science', 'humanities' etc.) are, to some degree, subjective, especially when researchers are increasingly working across disciplines. Nonetheless, the terms are meaningful.

The vast majority of researchers, in any country, would have little hesitation in classifying themselves as primarily a social science researcher or humanities researcher and so forth. In Australia there are four learned academies: the Australian Academy of Science (AAS); Association of Social Sciences in Australia (ASSA); Australian Academy of the Humanities (AAH); and Australian Academy of Technological Sciences and Engineering (ATSE). University organisational structures are generally constructed along broad disciplinary lines corresponding to the humanities, social science, science and applied technologies. Funding schemes, fellowships and other research opportunities are usually promoted in a likewise manner. The ARC itself assesses applications for funding using discipline-specific panels. Although there can be argument as to an exact definition of social science, or science, and researchers increasingly work within imprecise and interdisciplinary boundaries, it is nonetheless relatively straightforward to recognise a project that is driven primarily from the social sciences and distinguish it from, for example, one driven from the sciences. Thus, the present study offers a comparative approach to the analysis of researchers' experiences with the Linkage scheme.

\section{Data collection and method}

The data underlying this study was drawn from two sources. The first was the funding outcome reports for the Linkage Projects Scheme, covering the six-year application period 
2002-07. These were obtained from the ARC Website. A total of 6310 applications were submitted during this period, of which 2841 were funded. Of the 2841 applications funded, detailed data were extracted for 2605 projects. The discrepancy between the two numbers appears to be the result of a process of double-counting in some instances; that is, when an application was jointly considered - and recorded-across two or more Panels. (The ARC uses a College of Experts to assess applications, whose members assemble into broad groups to represent the humanities, social sciences etc.) These data provided the application success rates and amounts of funding for these projects. Each project included a primary Research Field, Courses and Disciplines (RFCD) code, which allowed the authors to assign it to a narrow (i.e. discipline) research field, as well as at the broader Academy level (see above).

The second data source was drawn from a number of interviews with individual researchers at a research-intensive university. Sixteen researchers were asked to reflect upon their prior experiences - both successful and unsuccessful-with the Linkage scheme. Their observations provided a rich layer of detail to complement the findings from the ARC data. The resulting analysis allowed the authors to build up a detailed picture of funding patterns and project characteristics for each Academy as detailed below.

\section{Academy dominance}

Dominance was measured by the percentage of overall Linkage funding secured by each Academy. At the macro level, dominance indicates government priorities through policy enactment, rather than avowed policy aims. At the meso level, dominance indicates, and can indeed influence, research focus and priorities for a university. ARC funding is a zerosum game and affects other recurrent government funding streams, which are allocated partly on ARC performance. In other words, the more funding a university receives through Linkage, the less funding is available to other institutions not only in Linkage, but via other government pipelines. At the micro level, dominance can act to send a message to scholars about the perceived value of their research.

\section{Average annual project funding}

Average project funding was measured on an annual basis (i.e. total Academy funding awarded divided by total grant years) to compensate for grants of varying lengths (i.e. between one and six years in duration). Although larger grants are not a guarantee of higher quality research, empirical studies have indicated a positive link between research funding and publications (Man et al., 2004), and have also found that the quality of published research is associated with the level of funding given to support the work underpinning it (Reed et al., 2007). In the UK, the Research Assessment Exercise (RAE) found a statistically significant link between higher levels of funding and research quality (Court, 1996). Furthermore, higher levels of funding arguably reinforce the funding-seeking behaviour of researchers, as it is associated with an affirmation of the importance of their research.

\section{Linkage partners}

A stratified sample was taken of all Linkage projects and, using sampling techniques adapted from Salant and Dillman (1994) and Rea and Parker (2005), the characteristics of the partners from 831 records were analysed. The breakdown of 109 humanities projects, 
212 applied technology projects, 246 social sciences projects and 264 sciences projects ensured that projects from each Academy were considered proportionate to the overall number of applications in the entire dataset. Partners were classified as either government or non-government entities. Government partners were subdivided into federal, State or local government authorities. Non-government partners were subdivided into not-forprofit (NFP), large and small-to-medium enterprises (SME). There is no standard or consistent definition of an SME internationally or for Australia. Definitions variously (and varyingly) consider the number of employees, annual profit/turnover and degree of internationalisation of the organisation. For the purposes of this study, an SME is defined as a company which: (1) employees fewer than 200 people; and (2) is not a subsidiary of a larger corporation. This analysis gave a comprehensive picture of both the number and type of partners researchers were engaging with, on their Linkage projects.

The number of partners on the grant is an important consideration for researchers, as administrative complexities and cost invariably rise in proportion to the number of collaborators involved. There are several reasons for this. First, in the development stage, the researcher(s) must devote significant time to build relationships with each partner. Second, during the application process, each partner agreement involves - and brings-a degree of bureaucracy to the application. For example, the chief investigator on a geophysical project interviewed for this study recounted the high degree of frustration he experienced in meeting the needs and expectations of each of his six partners, in particular the U.S. partners, who raised constant concerns about the legal implications of the research contract. Finally, the administrative burden continues throughout the life of the project, as each partner negotiates a contract, engages with the research, provides and receives project deliverables and assists in delivery of the outcomes.

\section{Research benefits}

Using the same stratified sample, the projects' 100-word summaries were analysed for evidence of the social, economic, cultural and other benefit of the project. The authors sought keywords, phrases or tropes that indicated what the author(s) believed would be the benefits of their project, both to the partners and the wider community. Keywords included 'benefit', 'improve', 'result' and 'provide'; as well as phrases 'This project will improve' and 'Significantly, this research will'. The process of content analysis was a largely qualitative process and did not identify the benefits of the project per se but, rather, the benefits as perceived and promoted by the researcher(s) who wrote the application. Hence, the summaries complement the findings of the analysis of partners, as the type of partners choosing to collaborate with the project can indicate the perceived benefits of the research project. For example, government departments tend to seek social outcomes in collaborative research projects, whereas studies have shown that profit organisations focus on areas with a high likelihood of financial returns, even when the overt motive for funding is for the benefit of the broader community (O'Brecht \& Doutriax, 1992).

\section{Findings}

\section{Academy dominance}

In the funding period 2002-07, Humanities projects accounted for less than seven per cent of all funded applications (6.7 per cent) and similarly less than seven per cent of all funds awarded (6.4 per cent). Most of this flowed to research involving architecture and the 
urban environment. During this period, not a single humanities discipline appeared in the top 20 fields of research funded by Linkage. By contrast, science projects dominated the Linkage scheme, with almost 40 per cent of funds going towards researchers associated with this Academy. Social science and applied technology researchers received a similar, healthy percentage of the funding pie, at approximately 27 per cent of funds awarded to each of these Academies. Furthermore, funding for humanities' projects has dropped by more than 15 per cent in real terms, over the six-year period analysed. At the same time the other three Academies have seen an average rise of 12 per cent. Researchers from the humanities now find it harder to attract funding from Linkage than they did when the scheme started.

Clearly, humanities researchers struggle to receive funding under a scheme designed to support all disciplines, including research that offers cultural benefits, pure basic research or simply 'the advancement of knowledge' (ARC, 2007). The perceived value of humanities research, insofar as Linkage funding indicates, is one of marginal concern. However, it is also true that the percentage of humanities applications funded was consistent with those from the other Academies. Forty-two per cent of humanities projects were approved, slightly over the median approval rate of 41 per cent for all Academies. Scholars in the humanities who do attempt to seek funding have just the same chance of success as those from other Academies. The attrition occurs before the application is made, rather than by the ARC itself. Rather than having their applications rejected at a disproportionate rate by the $\mathrm{ARC}$, the humanities researchers themselves appear to be unwilling and/or unable to submit applications. The analysis below reveals potential causes for this dearth of applications.

\section{Average annual project funding}

On average, humanities projects receive A $\$ 64464$ per annum, being significantly less than science and applied technology projects, which receive more than A\$75 000 per annum. Only social science projects fare worse, at only A\$61 500. However, whereas average social science funding has increased over the six-year period, that for humanities has decreased - the only Academy to do so. Therefore, not only do humanities scholars find it harder to attract funding from Linkage than they did in 2003, those that are successful have smaller project budgets to support the research.

The low project funding levels are, in part, a reflection of the contributions made by the project partners. Because the ARC will only match funds, lower partner contributions result in lower ARC funding. Humanities projects rely more on local government and NFP organisations, combined, than any other Academy, and these are the two sectors least able to commit large amounts of money to research. Contributions from these types of partners are more likely to be expressed as in-kind (e.g. staff time, access to data etc.) than actual cash. A humanities (historian) researcher who was interviewed, ruefully observed that 'potential partners in the humanities area are usually poorly funded like [university humanities departments]. . . Few private organisations can see benefit in supporting history projects.' One of the scheme's funding rules is a requirement that a minimum 20 per cent of support raised must be in cash. In many cases, this sets a very low funding ceiling above which humanities researchers cannot apply. Researchers from the humanities are therefore confronted with a dilemma - they must either increase the number of collaborators in an effort to raise sufficient cash, or decrease the amount of funding requested and complete the research under financial pressure. This is also true of their peers in the social sciences, one of whom believed that his application had failed because he had not been 
able to attract enough funding from the partner 'to demonstrate genuine commitment, thus the total budget was marginal in terms of what could be achieved'.

\section{Linkage partners}

At 2.2 partners per grant, humanities projects are the second highest of all Academies in the number of average partners per project. Coupled with their low levels of average annual funding, this means that humanities grants combine lower levels of return with higher levels of administrative complexity. Identifying partners and securing their support can be hard work. As one humanities scholar interviewed for this study observed, 'I had the idea [for the research project] in 1994, then spent nearly a decade lobbying premiers, ministers [and] State government departments.' For each partner on the grant, similar efforts must be made and then continued when the project is delivered. Indeed, researchers across all Academies spoke of the frustrations associated with administering a Linkage grant that arose out of communicating with, reporting to, and managing project partners. As the number of partners increases, so too does the potential for conflict amongst them. Furthermore, if and when the project changes direction (e.g. due to unforeseen environmental factors), then each partner must agree to the new research direction. Thus, researchers who tend to run projects with multiple partners, such as those in the humanities, often find the value of the research grant diminished.

Humanities researchers rely more on the government sector for funding than those from any other Academy, with more than half of all partners coming from the public sector. It would seem the humanities find it the hardest by far to engage with large businesses - only five per cent of humanities' partners come from this sector. By contrast, ATSE research partners are drawn predominantly from the private sector. Three out of four of their projects are either solely represented, or dominated, by private sector partners, not including NFP organisations. A reliance on government funding carries with it additional costs for the humanities researchers. First, many government organisations have their own funding processes, requiring the researcher not only to go through laborious Linkage application processes but prior to that, to undertake similar work for each government organisation. Second, in many cases the decision to approve funding support is taken at the ministerial level, who typically remains disengaged - even unaware - of the project until its latter stages of development. This can be exacerbated by government reshuffles. One researcher experienced frustration after dealing with a government organisation for several years and receiving ongoing expressions of support and indications that a significant financial commitment would be made. However, when she finally prepared for a Linkage application there was a change in senior management within the department. The new executive determined different priorities, which were not communicated to the researcher until she was about to submit her application. The consequence for the researcher was that two weeks before submission she was left trying to find another partner to contribute a significant amount of financial support for the project. Furthermore, if the project is approved, many government departments place quite strict reporting requirements upon the researchers, above and beyond those already stipulated by the ARC. All of these elements add to the frustration experienced by humanities researchers, as well as reducing the value of their research grants.

By way of contrast, ATSE and science grants tend to involve far fewer partners. This is particularly true of ATSE projects, which average only 1.4 partners and, furthermore, where four out of every five projects have only one partner to manage. This may assist these researchers in building stronger relationships prior to application to the Linkage 
scheme. An engineering researcher was successful on his first attempt at a Linkage project and accorded much of this success to the prior research he had undertaken with the partner. This prior research set the foundation for provisional patents and intellectual property (IP) agreements. As he remarked, 'Given the company was already supporting [the] R\&D, there were essentially no barriers in finalising the Linkage application.'

Dealing with fewer partners is also beneficial if the initial Linkage application is unsuccessful, as it is simpler to manage their disappointment, reinforce their relationship and re-group for another attempt. A scientist who was interviewed, an animal biologist, put in five unsuccessful applications for Linkage funding before the project was finally funded. Such perseverance is more likely to be rewarded when only one partner has to be kept motivated to re-apply for funding, rather than many.

Relying as it does on taxpayers' funds, there is an understandable expectation by the ARC that the research undertaken will benefit the wider community as well as the partner. In addition to requiring broad and open dissemination of the research findings, the Linkage scheme seeks to fund research that 'involves risk or innovation' (ARC, 2007, p. 9). Thus, although the specific fruits of the research might benefit the partner, it is hoped that it will also uncover systems, processes and technologies that can be applied elsewhere. Although the intellectual property (IP) cannot be monopolised by the partner, they benefit by having a head start on their opposition. Furthermore, the ARC subsidises research that may otherwise have been too risky, or uncertain of return, for the partner to consider funding themselves. However, this aspect of the Linkage scheme appears to be a stumbling block for some researchers from the humanities. As a historian remarked:

The ARC works on the assumption that innovative research is what the partner wants. Maybe this is what works in the sciences, or engineering, but in the humanities most partners are not looking for radical, new theories or methodological processes. What [the partner] wants is a tried and true method, applied to their particulars situation - so it's hard to meet the expectations of both the ARC and the partner.

\section{Research benefits}

The comparative lack of engagement with the private sector is perhaps explained by the way in which humanities researchers perceive the benefits of their research. Only onequarter of humanities projects analysed (the lowest percentage of all Academies) wrote of the economic benefit of their research. Neither did they speak overly of social benefitbarely one-third of projects' summaries referred to this type of capital accruing from their research, the second-lowest of all the Academies. Rather, humanities scholars preferred to focus on the cultural benefits of their projects. For example:

Both Australia and Turkey see the Gallipoli Campaign as a defining event ... Yet, despite the vast collection of material held in Turkish archives, existing accounts give scant attention to Turkish operations, leaving the story incomplete. This project will rectify that imbalance by locating and translating key documents ... The result will be a comprehensive history that will contribute to the deepening relationship between Australia and Turkey as we approach the centenary of the Campaign.

This summary, like so many others, does not seek to speak of the economic or social benefit of its research, despite the opportunity offered by framing the research in the overall context of Australian-Turkish relations (e.g. political, trade or immigrant/emigrant opportunities). 
It also appears that humanities scholars often struggle, or at least do not attempt, to define any explicit social, economic or cultural benefit of their research. More than onequarter of the summaries referred only to what the research was, not what it set out to achieve. For example:

The project heralds a nationally significant co-operation between Australian cultural and tertiary institutions to research the content impact and legacy of Australian tours 1936-40 by the acclaimed Ballets Russes . . . Research will generate a range of scholarly publications, physical and virtual exhibitions and select performances by the Australian Ballet. The project utilises an innovative interactive research methodology to establish a vital nexus between scholarly research digital archival management and dissemination strategies and artistic practice.

It is important to note that the content being analysed here is the project summary, not a summary of national benefit. Hence, researchers are not obliged to make claims of benefit in this part of the application. However, it is equally important to note that researchers associated with the other Academies were eager to explicate benefit in this section of the application, whereas humanities scholars were not. More than one-quarter (i.e. 26.6 per cent) of humanities' project summaries failed to define a benefit, more than twice that of the next highest (ATSE, at 12.7 per cent). This indicates that humanities scholars have more difficulty framing their research in the same way as the other Academies.

ATSE and science researchers were far more comfortable arguing socioeconomic benefit, although there was a perceptible difference between the ways in which the two did so. ATSE focused strongly on the economic aspect of socioeconomic, and particularly of the direct benefit to the partner(s) involved. ATSE researchers were much more likely to explicate the direct and commercial benefit to their partners by using statements such as: 'This project will improve the competitiveness of the manufacturer' or 'Benefits from this research include competitive advantage to [the] operators'. A total of 27 out of 135 ATSE grants that promoted economic benefit linked such benefit directly to their partner(s) in phrases such as these. By contrast, science researchers accentuated the social aspect of socioeconomic by linking research outcomes to broader community benefit. For example:

The expected outcomes of this project will be the conservation of hundreds of thousands of juvenile fish, ensuring a better fishery whilst also securing the economic and social structure of coastal communities that support this fishery.

The concept of 'sustainability' was most likely to appear in science projects. Of 98 projects referring to sustainability as a goal, outcome or benefit, close to half (44) were science projects. Often, the ideas of socioeconomic benefit and sustainability were combined, such as:

Commercial recreational and managerial sectors are collaborating with this research to ensure sustainable management of this commercially important and ecologically crucial species.

On the relatively rare occasions that economic benefit was argued by humanities researchers, it was most usually argued in social terms, used in conjunction with concepts of affordability, social responsibility or access for disadvantaged groups. Thus, affordable housing, reduced costs for public transport, or economic prosperity through national Indigenous reconciliation were all argued as indicators of economic benefit. 


\section{Conclusion}

Very few humanities projects are funded under the Linkage Projects scheme. Most of these projects struggle to explain the benefit of their research to either their partners or the wider community. Those that do succeed in this respect tend to focus on the cultural benefits of their research. Humanities scholars regularly fail to find partners willing to support their research and often will engage with multiple partners, not primarily because they are a 'natural fit' for the project but because they require additional financial support to achieve the project outcomes. The resulting project, if funded, is typified by lower-than-average funding levels and higher-than-average maintenance costs.

In fact, almost exactly the same comment could be made for social science researchers. Their projects are also characterised by high numbers of partners and low levels of funding - indeed, higher and lower in both respects to their colleagues in the humanities. However, the social scientists appear to have two significant advantages over their colleagues in the humanities. First, social scientists are more able to 'talk' the language required by the Linkage scheme. Second, far more projects are funded under the scheme than are those from the humanities. The ARC appears much more willing to fund projects with social outcomes, over cultural ones. Consequently, they are more likely to be considered by policy actors when government policy is being formed. Thus, there is a greater argument for institutions to support their research and deal with the funding shortfalls. After all, unlike the humanities researchers, social scientists have a greater claim to argue that their research, at the meso level, has a significant impact on the university's research income and thus its international standing.

Despite its avowed aims, the Linkage scheme does not seem to value equally all research. The scheme's strategies and key performance indicators (KPIs), as outlined in ARC's Strategic Action Plan 2003-05, indicate an economically rationalistic policy (ARC, 2003). Strategies include: the establishment of industry fellowships to support researcher mobility between universities and private industry; workshops to promote technology transfer between universities and the private sector; lobbying APEC trade forums and international trade fairs to link into global markets; and developing an alliance between the ARC and the Business Council of Australia. The KPIs include evidence that the Linkage scheme encourages universities to commercialise their research, and increased opportunities for venture capital firms to invest in the research outcomes of projects funded under the scheme. None of the strategies or KPIs listed relate directly to social or cultural benefits. Furthermore, the ARC consistently refers to the end user as a 'partner' (specifically, a Partner Organisation) - a term that designates economic ties (Irving \& English, 2008). There is evidence, therefore, of a hierarchy of knowledge being valued in government policy. Although the Linkage scheme notionally supports research leading to social, economic or cultural benefits, the underlying language, strategies and performance indicators imply that research which can point towards economic success will be favoured. The criteria for success in Linkage are harder to achieve for the humanities than researchers from any other Academy.

Perhaps the time has come to separate humanities research funding completely from that of the sciences, to fund it uniquely and exclusively, to desist in asking it to compete on unequal terms by trying to be something it is not. This would at least have the advantage of making more transparent the price put on its value by policy actors. Education policy researchers have elsewhere argued that if we are required to report, count, are funded, and are held accountable for something, it starts to matter a lot. It encourages institutions to put in place mechanisms for its support and for champions to raise the issue 
and push for its further development (Wheelahan et al., 2003, p. 41). The same may well be true for how humanities research is funded in the future. Perhaps it is time to give humanities scholars their own, exclusive research funds and exclude them from more mainstream ones, if for no other reason than to make the actions of all involved - the government, the universities, the researchers and the end users-more transparent and accountable.

\section{Acknowledgement}

The authors thank the editors and anonymous referees for their constructive comments on an earlier version of this paper. Any opinions expressed or errors contained in this article are those of the authors alone.

\section{References}

Australian Research Council [ARC]. (2003). Strategic plan (online). Retrieved October 7, 2008, from http://www.arc.gov.au/about arc/strategic plan.htm

Australian Research Council [ARC]. (2007). Linkage projects Funding rules for funding commencing in 2008. Online document retrieved November 25, 2008, from http://www.arc.gov.au/ applicants/fundingRules.htm

Australian Research Council [ARC]. (2008). Strategic plan (online). Retrieved October 7, 2008, from http://www.arc.gov.au/about_arc/strategic_plan.htm

Berman, J. (2008). Connecting with industry: Bridging the divide. Journal of Higher Education Policy and Management, 30(2), 165-174.

Buys, N., \& Bursnall, S. (2007). Establishing university-community partnerships: Processes and benefits. Journal of Higher Education Policy and Management, 29(1), 73-86.

Carr, K. (2008). The art of innovation. Address to the National Press Club, September 3, 2008. Retrieved January 16, 2009, from http://minister.innovation.gov.au/

Court, S. (1996, July 12). Checking links of quality and funding. Times Higher Education (online edition). Retrieved November 27, 2008, from http://www.timeshighereducation.co.uk/ story.asp?storyCode $=99959 \&$ sectioncode $=26$

Goldsworthy, J. (2008). Research grant mania. Australian Universities Review, 50(2), 17-24.

Irving, C., \& English, L. (2008) Partnering for research: A critical discourse analysis, Studies in Continuing Education, 30(2), 107-118.

Kirkland, J. (2008). University research management: An emerging profession in the developing world. Technology Analysis \& Strategic Management, 20(6), 717-726.

Lazarevski, K., Irvine, H., \& Dolnicar, S. (2008). The effect of funding changes on public sector nonprofit organisations: The case of Bushcare NSW. Journal of Nonprofit \& Public Sector Marketing, 20(2), 213-227.

Lee, J. (2007). The shaping of the departmental culture: Measuring the relative influences of the institution and discipline. Journal of Higher Education Policy and Management, 29(1), 41-55.

Man, J., Weinkauf, J., Tsang, M., Hogg, J., \& Sin, D. (2004). Why do some countries publish more than others? An international comparison of research funding, English proficiency and publication output in highly ranked general medical journals. European Journal of Epidemiology, 19(8), 811-817.

Marginson, S. (2000). The enterprise university in Australia. Leading \& Managing, 6(2), 98-112.

Marginson, S. (2006). Dynamics of national and global competition in higher education. Higher Education, 52, 1-39.

Marginson, S. (2007). University mission and identity for a post post-public era. Higher Education Research \& Development, 26(1), 117-131.

Marinova, D., \& Newman, P. (2008). The changing research funding regime in Australia and academic productivity. Mathematics and Computers in Simulation, 78(2/3), 283-291.

O'Brecht, M., \& Doutriaux (1992). Impact of the private non-profit sector on the distribution of Canadian health research. Canadian Public Policy, 18(3), 290-299.

Rea, L., \& Parker, R. (2005). Survey research: A comprehensive guide. San Francisco, CA: Jossey-Bass. 
Reed, D., Cook, D., Beckman, T., Levine, B., Kern, D., \& Wright, S. (2007). Association between funding and quality of published medical education research. Journal of the American Medical Association, 298(9), 1002-1009.

Salant, P., \& Dillman, D. (1994). How to conduct your own survey. Toronto: John Wiley \& Sons.

Shattock, M. (1999). Governance and management in universities: The way we live now. Journal of Education Policy, 14(3), 271-282.

Turpin, T., \& Deville, A. (1995) Research management and commercial markets: Cultural change in Australian research institutions. Prometheus, 13(1), 45-61.

Wheelahan, L., Dennis, N., Firth, J., Miller, P., Newton, D., Pascoe, S., Veenker, P. (2003). Recognition of prior learning: Policy and practice in Australia. Report commissioned by the Australian Qualifications Framework Advisory Board. Retrieved February 5, 2007, from http:// www.scu.edu.au/research/rpl/

Wood, F., \& Meek, L. (2002). Over-reviewed and under-funded? The evolving policy context of Australian higher education research and development. Journal of Higher Education Policy and Management, 24(1), 7-25.

Yokoyama, K. (2006). Entrepreneurialism in Japanese and UK universities: Governance, management, leadership, and funding. Higher Education, 52, 523-555. 